Янь Лю

\title{
ОСОЗНАНИЕ ПРАВ И ПРАВИЛ СЕЛЬСКИМИ ПРОТЕСТУЮЩИМИ В КИТАЕ (НА ПРИМЕРЕ ПРОТЕСТОВ В СЕЛЕ УКАНЬ)
}

Осознание прав китайскими сельскими протестующими в основном изучается в контексте демократических правовых отношений между государством и гражданами. При этом недостаточно внимания уделяется связи с использованием протестующими социалистического учения, сельской культуры и других идеологем. В немногих исследованиях, посвященных этой проблематике, обсуждается главным образом только осознание прав выживания. Между тем актуализируется задача понимания того, каким образом характеризуется осознание прав и правил протестующими в современном сельском обществе Китая, где выживанию жителей села уже ничего не угрожает. В качестве объекта исследования используются протесты в селе Укань провинции Гуандун Китая. Влияние идеологем на осознание прав и правил изучается методом фрейм-анализа. Эмпирическую базу исследования составили материалы (тексты, фото- и видеозаписи), отражающие ход протестов и заявления сторон конфликтов. Показано, что жители Уканя протестовали, поскольку считали распределение доходов от сделок с коллективной землей несправедливым. Требования протестующих касаются не выживания, а главным образом защиты экономических интересов. Осознание прав жителями Уканя формируется на базе сельской культуры и партийной идеологии и отличается от осознания гражданских прав, потому что, хотя требования протестующих не защищаются законом, сельчане не ставили под сомнение правомерность существующих законов и политики. Осознание прав на основе сельской культуры усиливает интенсивность протестов, а осознание прав на базе партийной идеологии предполагает укрепление авторитета центральных органов государства и компартии. Заимствование дискурса о социалистической революции

Янь Лю - соискатель, научный сотрудник, Центр китайского сельского исследования, Центральный китайский педагогический университет, Ухань, Китай. Электронная почта: karenly_62@mail.ru 
придает протестам оттенок классовой борьбы. Так как в Китае коллективные действия с самого начала сталкиваются с кризисом законности, осознание правил касается необходимости легитимации протестных действий. В этом и отражается роль официальной идеологии Китая (принципа верховенства права и партийной идеологии) в «деполитизации» сельских протестов.

Ключевые слова: фрейм коллективного действия, партийная идеология, верховенство права, гражданские права, сельские протесты, реквизиция земли

DOI: $10.17323 / 727-0634-2018-16-2-327-340$

С начала 1990-х гг. в Китае у сельских жителей проявляется тенденция цитировать официальные законы и ссылаться на государственную политику в целях оправдания коллективных протестов. Эту тенденцию политологи Кевин О’Брайен и Ли Ляньцзян называют rightful resistance - «правомерным сопротивлением», в котором отражается растущее «осознание прав» (rights consciousness) рядовыми китайцами (O’Brien, Li 2006; Zweig 2010). Многие исследователи оценивают этот социальный феномен как возможное изменение отношений между государством и обществом Китая, а также как потенциальный вызов коммунистическому режиму КНР (Perry 2007).

Надо отметить, что Элизабет Перри понимает означенную тенденцию по-своему - как «осознание правил» (rules consciousness), а сама тенденция интерпретируется ею как повышенная чувствительность рядовых китайцев к сигналам от государства, идущим сверху вниз (Perry 2007). С ее точки зрения, протестующие в современном Китае принимают господствующий дискурс прав, подобно тому, как протестующие в эпоху Мао заимствовали тогдашний дискурс классового общества. Протесты на основе осознания правил укрепляют легитимность государственной власти. Соглашаясь с Перри, Ли понимает осознание правил как понимание «необходимости защиты себя от местных правоохранительных органов» (Li 2010: 50). Далее он вводит понятие «осознание прав» и определяет его как способ защиты себя от центральных нормотворческих органов, а именно как необходимость изменения правил, если права не защищаются правилами ( $\mathrm{Li} 2010)$. В некоторых исследованиях утверждается, что осознание прав такого рода в протестах китайских рабочих и крестьян пока не проявляется (Cheng 2012; Yu 2009), тогда как другие работы доказывают, что у трудящихся имеется осознание прав (Franceschini et al. 2016).

Поскольку многие ученые (Cheng 2012; Li 2010) определяют осознание прав в контексте демократических отношений между государством и гражданами, они подчеркивают внутренние связи между гражданством и правовыми актами. При этом не учитывается возможность наличия в Китае связей между осознанием прав и традиционной культурой или социалистическим 
учением. Перри, анализируя этические дискурсы китайских древних философов, политических лидеров и протестующих, предлагает своеобычную китайскую концепцию «прав», центрированную на праве выживания: китайцы считают, что они имеют естественное право предъявления к государству требования обеспечения им экономической безопасности (Perry 2008). Работа Перри показывает актуальность осмысления проблемы осознания прав и правил с точки зрения использования протестующими различных идеологем. С учетом этой исследовательской задачи осознание прав определяется нами, как осознание необходимости защищать интересы, которые считаются протестующими достойными, но не полностью защищаются законом, а осознание правил, как готовность протестующих привести коллективные действия в соответствие с сигналами от государства.

Вместе с тем сохраняется актуальность понимания механизма осознания прав протестующими в сельских районах Китая, где выживанию ничего не угрожает. Это частично объясняет выбор в качестве объекта исследования протестов в селе Укань, которому, благодаря экономическим достижениям, присвоили звание «первого села в городе Шаньвэй провинции Гуандун» (Lin, Chen 2008). Эмпирическую базу исследования составили тексты и фото (открытые письма, жалобы, лозунги и транспаранты, записи собраний активистов, их блоги и микроблоги, официальные документы), видеозаписи (о ходе протестов и интервью с протестующими, снятые активистами, учеными и масс-медиа, видеозаписи о выступлениях местных чиновников). Доступ к материалам получен через Интернет: протестующие записывали процесс с помощью видеокамер и загружали видео, фото и тексты в социальные сети.

\section{Микромобилизация, фреймы и сельские протесты в Китае}

Теоретический синтез таких подходов к анализу протестных действий, как теории политического процесса, мобилизации ресурсов, новых социальных движений и социального конструктивизма позволяет изучать макро-, мезо- и микро- аспекты мобилизации коллективных действий (Zuo, Benford 1995). Анализ макромобилизации фокусируется на политических возможностях, возникающих в институциальной структуре и социальных процессах (Tarrow 1983; McAdam 1982). В сельском Китае структурные триггеры протестов против реквизиции земли, в том числе в Укани (Zeng, Zhang 2015), связаны с проблемами коллективной собственности на землю, недостатками системы управления земельными ресурсами и кризисом сельского управления (He 2010; Guo 2001), а также с урбанизацией, фискальной политикой и экономической моделью КНР (Ong 2012). Противоречия между центральными и местными органами власти в государственной политике поддержки крестьян побуждает сельских жителей 
участвовать в действиях сопротивления (Zweig 2016; O’Brien, Li 2006). В этой связи динамика протестов в Укани изучается в разрезе взаимодействия между сельским обществом и органами власти разных уровней (Нuа et al. 2016; Zeng, Zhang 2015).

Анализ мезомобилизации ориентируется на изучение ресурсов, определяющих репертуар, тактику, организацию протестных действий (Morris 1984; McCarthy, Zald 1977). Сплоченные сообщества, руководство протестами, социальные связи, поддержка общественностью и масс-медиа характерны для успешного сопротивления в сельской местности (Zhang 2015; Michelson 2007), в том числе в Укани, где особый акцент сделан на клане как автономной организации и медиаактивизме ( $\mathrm{Lu}$ et al. 2017; Hess 2015; Не, Хue 2014). Как в селе Укань (Hua et al. 2016; Zeng 2013), так и в других селах (Yu 2009), протесты направлены против низовых чиновников, и популярные репертуары включают петиции, «оружие слабых» (Scott 1985), массовые демонстрации и насильственные действия.

Предмет нашего исследования связывается с микромобилизацией коммуникативным процессом смыслового производства, влияющим на восприятие людьми ситуации как проблемы и стимулирующим их участие в коллективных действиях (Snow, Benford 1988; Snow et al. 1986). В рамках теории фрейма микромобилизация рассматривается как актуализация фрейма коллективного действия (ФКД), а именно как связывание интерпретирующих схем индивидов и лидеров протеста таким образом, чтобы их набор интересов, убеждений и целей обрели конгруэнтность и дополняемость (Snow et al. 1986: 464). Создание ФКД ограничивается политико-культурными внешними факторами (Koopmans, Statham 1999: 228).

Помимо материальных выгод, осознание прав, чувство несправедливости и обделенности служат стимулами участия в протестах (Perry 2008; Michelson 2007). Хотя исследования подтверждают значимость для возникновения и организации протестов в Китае таких социально-идеологических феноменов как сельская культура и этика (Ying 2007), социалистические ценности (Feng 2013), более детальное объяснение этого процесса требует дополнительных «этнографических исследований, <..> направленных на изучение самоидентичности крестьян, сельских общин, культурных норм и местной истории» (Yeh et al. 2013:921). Предыдущие исследования уже выяснили роль местной религии (Hou 2013), культуры клана (He, Xue 2014) и дискурса прав (Lu et al. 2017) в создании коллективной идентичности в Укани. Данная статья фокусируется на том, как совокупность идеологем влияет на осознание прав и правил протестующими Уканя.

Этот вопрос изучается методом фрейм-анализа. Согласно теории фрейма, «[т]е элементы и процессы, которые человек использует для истолкования своей деятельности, часто есть то, что деятельность сама в себе обнаруживает» (Goffman 1986: 26), поэтому процесс осознания прав и правил можно проследить через анализ деятельности протестующих. 
В связи с тем, что актуализация ФКД определяется процессом конструирования конкретных микросистем смыслов на основе выбора убеждений из комплекса идеологий и их артикуляции (Steinberg 1998: 856), анализ ФКД позволяет объяснить связи социокультурной структуры с протестными действиями и, следовательно, с осознанием прав и правил.

\section{Протесты в селе Укань: дискурс и репертуары}

Появление новых лидеров, изменение стратегий действия, реакция правительства и другие события влекли за собой изменения ФКД. Путем анализа диагностического, прогностического и мобилизационного аспектов протестов (Snow, Benford 1988) выделим четыре ФКД, поочередно используемых на всех этапах протестов в Укани. Здесь особое внимание обращается на влияние идеологических установок на дискурсивные стратегии протестующих и репертуары протеста. Большинство идеологем оказывало влияние на протяжении всего периода столкновений, но их важность для каждого из этапов была различной. На основе этого соединяются ФКД и идеологические положения.

\section{Относительная депривация}

С июня 2009 г. до 21 сентября 2011 г. главной формой коллективных действий являлись жалобы молодых активистов в правовые инстанции и местные правительства. Было написано 11 жалоб и предъявлены требования по организации сельских перевыборов, возвращению незаконно проданной земли и по гарантиям открытости сельской администрации, но это не принесло результата. После последней петиции 14 марта 2011 г. активисты переключились на мобилизацию сельских жителей. В открытом письме «Не будем рабами без села» (Zhuang 2009) активисты напомнили жителям Уканя об их материальных потерях: (1) они почти не получили никакой компенсации за проданные коллективные земли; (2) коллективный доход попал в руки сельских чиновников и влиятельных кланов; (3) жители в других селах получали дивиденды от распределения коллективного заработка, но население Уканя было лишено этой возможности. Эти факты вызывали у сельчан чувство «относительной депривации», под которой понимается переживание гнева, обиды и недовольства, вызванное тем, что люди чувствуют себя лишенными чего-то, чем они должны бы быть наделены (Runciman 1966).

Ощущение лишенности приобретало особую остроту благодаря сельской семейной культуре, к которой апеллировали активисты, подчеркивающие значение земли для предков и потомков: «Без земли как можно жить нашим детям?», «Вряд ли мы можем только беспомощио взирать, как уходит имущество наших предков из рук нашего поколения» (Zhang 2012). Традиционно несколько поколений одной крестьянской 
семьи живет на одном месте и на основе этого формируются общие семейные, клановые и сельские интересы, чувство долга по отношению к предкам и потомкам, любовь к земле. С помощью дискурса такого рода жители Уканя представляли протесты как защиту имущества предков и потомков.

Кроме того, используя дискурс о борьбе за национальную независимость, протестующие представляли сельских чиновников в качестве врагов, которые должны быть изгнаны: «Эти коррупционеры в шкуре коммунистов занимались грязными делами как японские душегубы» (Zhang 2012). Националистические мотивы способствовали обострению гнева.

\section{Протест с возмущением}

Коллективная петиция 21 сентября 2011 г. появилась как результат предыдущих эпизодов мобилизации и реакция на слух о том, что сельский комитет вместе с гонконгским бизнесменом Ченом передал последний участок земли застройщику и присвоил несколько сотен миллионов юаней компенсации. Узнав об этом, около двух тыс. жителей Уканя подошли к дому правительства уезда Луфэн и затем к сельскому комитету для подачи жалобы. Поскольку ответ не удовлетворил селян, протестующие штурмовали сельский комитет, повредили имущество бизнесмена Чена и застройщика, а также забаррикадировали дороги. На следующий день жители села осадили сельский комитет и полицейский участок, чтобы освободить четверых арестованных во время вчерашнего конфликта жителей. Им противостояло около 200 полицейских. Наличие полиции, а также слух о том, что они убили двоих детей, повысили недовольство протестующих и привели к эскалации конфликта. Результатом стало изгнание сельских чиновников и отступление полиции.

«Протест с возмущением» возник на волне распространившихся слухов. Восприятие жителями происходящего определялось не организаторами протеста, а формировалось в спонтанном развитии массового сознания. Активисты считали коррупцию сельских чиновников основной причиной расхищения земли, а остальные жители были склонны обвинять бизнесменов: «Чен, как жук-мироед Уканя, сделал всё возможное, чтобы урвать земли» (Zhang 2012). Им казалось, что Чен (бывший житель Уканя) «предал своих земляков, подкупил сельский комитет и местное правительство» (там же) и даже полицию, противостоявшую жителям 22 сентября.

При отсутствии точной информации интуитивное понимание сельчанами проблемы строилось на основе социальной установки «враждебности по отношению к богатым и чиновникам». На это имелись свои причины. В ходе китайских реформ произошло срастание местной власти и предпринимателей, которые постепенно становились привилегированными классами общества (Ong 2012). Разрыв между богатыми и бедными сегодня раздражает рядовых китайцев и способствует росту общественной враждебности. 


\section{Правомерное сопротивление}

Правительство уезда Луфэн насильственные коллективные действия 21-22 сентября объявило преступными и призвало подавить беспорядки. В этих условиях пользующийся авторитетом 68-летний житель села Линь Цзулуань согласился руководить протестами. Он вместе с активистами образовал сельский временный комитет. С этого момента протесты приобрели организованный характер и сдвинулись в сторону «правомерного сопротивления».

Лидеры протеста выступали за мирное сопротивление, убеждали жителей избегать противоправных действий и защищать интересы в соответствии с законом. На транспарантах стало чаще использоваться слово «закон»: «Против незаконного захвата земли», «Против незаконных выборов» (Zhang 2012). Протестующие, с одной стороны, по официальным каналам по-прежнему подавали жалобы, а с другой, прибегали к полузаконным действиям, как способу давления на местную власть: 21 ноября они еще раз провели массовую демонстрацию.

На этом этапе впервые оформилось главное требование жителей Уканя: «Верните нам каждый кусок проданных земель!» (там же). С точки зрения протестующих, продажа земли считалась незаконной, потому что решения были приняты тайно. Однако их требование невозможно было удовлетворить в рамках правовой системы Китая, так как большинство земель было продано в 1990-х и начале 2000-х гг., когда коллективная собственность жителей на потерянную землю уже была изменена на государственную собственность в соответствии с законом. Пока в Китае отсутствует правовая основа аннулирования таких контрактов или возмещения ущерба.

Активисты знали, что их проблема была связана с недостатками политики управления землей: «Бизнесмень, пользуясь пробелом в законодательстве, получали право пользования на земли» (RTHK 2012). Однако они не ставили внесение изменений в законодательство в качестве цели, а ограничивались требованием возвращения потерянных участков: « $\mathrm{Mbl}$ были бы удовлетворень, если бы наша земельная проблема могла быть решена» (там же). Активисты даже отказали в просьбе жителям соседних сел присоединиться к протестам, чтобы коллективные действия Уканя не превратились в социальное движение, выступающее за проведение реформы.

Пока в нормативной плоскости проблема не могла разрешится быстро и так, как ожидали протестующие, они возлагали надежду на вмешательство вышестоящих органов власти и искали поддержку в риторике партийной идеологии. Обвинив сельских чиновников в коррупции («Долой коррупциионеров»), жители Уканя частично превратили протесты в антикоррупционное массовое движение, которое, как способ укрепления авторитета КПК, пользуется высокой легитимностью. Кроме того, дискурс борьбы с коррупцией был полезен для делигитимации сельского комитета и дальнейшего отрицания законности принятых им решений о продаже 
земель: «Как можно доверять и опираться на такое правительство? Настоящзая компартия [кадры высших органов власти], обратите, пожалуйста, внимание на это!» (Zhuang 2009).

С целью оправдания своих действий и обретения поддержки от вышестоящей власти, протестующие также апеллировали к «отношениям между партией и массами». Следуя логике того, что компартия всегда защищают интересы масс, жители Уканя использовали лозунг «Да здравствует компартия» и много раз говорили, что «без изентрального правительства мы не можем решить проблемы» (Zhang 2012). Лидер протеста Линь также подчеркивал свое членство в КПК: «Почему под огромным давлением я настаиваю на сопротивлении <...> потому что я член КПК и должен придерживаться духа партии» (SunTV 2012).

Дискурс о социалистической революции косвенным образом использован для мобилизации сельских жителей, но не для определения проблемы и ее решения. Протестующие пели государственный гимн КНР, «Интернационал» и другие революционные песни. Активисты назначили коллективную петицию на 21 ноября. В этот день в 1927 г. Пэн Бай создал первый в Китае крестьянский совет в Хайлуфэн (бывшее название уезда Луфэн). Местная религиозная культура также способствовала возникновению протестов (Ноu 2013).

\section{Борьба за «Ци»}

Однозначно отрицательная оценка протестов со стороны местной власти, а также арест избранных жителями депутатов 4-9 декабря 2011 г. вызвали у сельчан негативные эмоции. Смерть 11 декабря в тюрьме депутата Сю Цзиньбо стала последней каплей, переполнившей терпение жителей Уканя. Печаль, гнев, страх и обида временно превратили борьбу против продажи земли в «борьбу за признание», когда материальная компенсация, предложенная городским правительством, уже не могла успокоить жителей. Они в первую очередь требовали от правительства признать справедливость их коллективных действий.

На этом этапе «мотивы для социального сопротивления и бунта формируются в контексте морального опыта, вытекающего из нарушения глубоко укоренившихся ожиданий в отношении признания» (Honneth 1996: 163). Китайский социолог Ин Син называет моральный опыт такого рода китайским традиционным словом «Ци», указывая на его связь с сельской социальной этикой (Ying 2007). Жители Уканя отчаянно протестовали, укрепляя «Ци» двумя способами. Во-первых, они делали акцент на обиде, боли и бедности. Протестующие каждый день проводили сидячие забастовки, оплакивали смерть Сю и скандировали лозунги «Жители Уканя терпят несправедливость», «Где же небесньле принципьл?» (Zhang 2012). Во-вторых, они выражали решимость бороться любой ценой: «Один человек уnал, mьсячи встали», «Кровь за кровь», «Скорее умрем, чем сдадимся» (там же). 
Протесты утихли только после 20 декабря, когда провинциальное правительство признало их правомерными.

Сельская социальная этика, на которой основывается «Ци» как когнитивная модель, изоморфна с конфуцианской патриархальной системой (Shih 2010). Эта изоморфность формирует у сельских жителей привычку оценивать современный политический порядок с точки зрения этики повседневной жизни. Словосочетания «высшая справедливость», «космическая власть» и «небесные принципы», чаше всего используемые на этом этапе, представляют высшую власть справедливости, авторитет которой при борьбе за «Ци» в глазах сельских жителей выше закона.

\section{Заключение}

Протесты в Укани вызваны не кризисом выживания, а несправедливым распределением доходов от сделок с коллективной землей, в результате сельчане стали непривилегированным социальным классом. В этом проявилась относительная депривация протестующих. И их требования в основном касались защиты экономических интересов. Жители Уканя требовали возвращения проданных земель. Хотя их запросы уже вышли за рамки закона, они все еще претендовали на право их защищать. В этом отражается осознание прав в противовес правилам. Столкнувшись с тем, что их основные потребности не защищаются законом, они не ставили под сомнение правомерность законов и политики, а обвиняли аморальных алчных бизнесменов и местных чиновников в использовании «слепой зоны» закона. Тем не менее борьба не была направлена на изменение правил. В этом ключе осознание прав жителями Уканя отличается от осознания гражданских прав, определяемого Ли (Li 2010).

В протестах Уканя осознание прав формируется на базе сельской культуры и партийной идеологии. Активисты, исходя из сельской семейной культуры, подчеркивали, что земельные ресурсы принадлежат крестьянам, и с позиций сельских традиций требовали, чтобы правительство действовало согласно высшей справедливости. Так как наиболее напряженное сопротивление возникло на этапах «протеста с возмущением» и «борьбы за “Ци”», основанных преимущественно на сельской идеологии, можно прийти к выводу, что осознание прав, базирующееся на сельской культуре, способно усиливать интенсивность протестов.

Партийная идеология также способствует осознанию прав. Ссылаясь на «отношения между партией и массами», протестующие заявили о своих правах пользоваться благами экономического развития села и искали защиты интересов у государства и компартии. Используя партийную идеологию, протестующие во время пика противостояния с местным правительством поддерживали тем самым лидерство компартии и возлагали надежду на центральное и провинциальное правительства. Более того, с помощью партийной 
идеологии жители Уканя противопоставляли справедливое центральное правительство и коррумпированную местную власть. Их протестные действия против местной власти усилили легитимность центральной. Поэтому осознание прав, базирующееся на партийной идеологии, предполагает укрепление авторитета государства и компартии.

Осознание правил связывается с использованием принципа верховенства права и правовых норм. Опираясь на верховенство права, лидеры протеста ограничились законными и полузаконным стратегиями. На самом деле, если бы это было не так, то протесты могли бы трактоваться местной властью как преступление в соответствии с официальной идеологией «Вэйвень» («Сохранение политической стабильности»). Таким образом, так как в авторитарном Китае коллективные действия с самого начала сталкиваются с кризисом законности, осознание правил касается необходимости легитимации протестных действий. Именно поэтому протестующие часто ссылались на партийную идеологию.

Как принцип верховенства права уменьшает насилие во время протестов, так и партийная идеология предотвращает обострение конфликта. Благодаря использованию дискурса о борьбе с коррупцией жители Уканя посчитали причиной их земельной проблемы порочность сельских чиновников, а не структурные недостатки, к примеру, «девелопментализм», продажу земель в качестве главных финансовых доходов местного правительства (Zeng, Zhang 2015). Это делает протесты менее политизированными.

Для анализа других идеологем материала недостаточно, но вероятно, осознание прав под влиянием остаточных (residual) и возникающих (emergent) идеологических парадигм (Williams 1977: 121) имеет тенденцию к радикализации протестов. Например, заимствование дискурса о социалистической революции придает коллективным действиям Уканя оттенок классовой борьбы и наделяет их потенциалом бросить вызов враждебному классу чиновников и бизнесменов. С другой стороны, лишь фрагментарное, частичное использование активистами Уканя этого дискурса показывает, что за тридцать лет реформ в Китае революционный дух классовой борьбы заменен новой официальной идеологией, и сельские жители, ранее бывшие передовым классовым отрядом, сегодня деполитизируются официальной идеологией как «массы», «народ» и «граждане» (Wang, Connery 2006).

С позиции общественной стабильности можно предположить, что поскольку верховенство права наиболее эффективно уменьшает насильственность и радикальность протестов, правительство Китая должно усовершенствовать правовую систему, чтобы разрешение социальных конфликтов регулировалось законом. Для этого нормотворческим органам необходимо уделять особое внимание осознанию сельскими жителями собственных прав и влиянию идеологии на этот процесс, чтобы правовая система отвечала потребностям и ожиданиям сельчан. Это способствует готовности сельских жителей защищать права в правовых рамках. 
Yan Liu

\title{
RIGHTS CONSCIOUSNESS AND RULES CONSCIOUSNESS AMONG RURAL PROTESTERS IN CHINA: AN ANALYSIS OF THE WUKAN INCIDENT
}

\begin{abstract}
The rights consciousness of Chinese rural protesters is mainly studied in the context of democratic legal relations between state and citizens. This has meant insufficient attention has been paid to the relations between rights consciousness and the protesters' adoption of socialist doctrine, rural culture, and other ideologies. Nevertheless, the few studies devoted to this problem have largely discussed the consciousness of subsistence rights. It is of particular importance to analyze the rights/rules consciousness of protesters in the more economically developed rural society of China, where the subsistence of village residents is not threatened. Based on this research interest, the Wukan protests are analyzed, and the influence of ideological packages on rights/rules consciousness are studied by employing the method of frameanalysis. The data analysed here consist of texts, photos, and videos that present the actual protest scenes and discourse of protesters, as well as the response of local governments. The results show that Wukan residents protested because they believed that the distribution of income from transactions with collective land was unfair, resulting in them becoming an underprivileged social class. The rights consciousness of Wukan residents is shaped on the basis of party ideology and rural culture, and differs from civil rights consciousness. Rights consciousness on the basis of rural culture intensifies protests, while rights consciousness based on party ideology strengthens the authority of the Communist Party. Rules consciousness is concerned with the need to legitimize protest, which leads to a decrease in the violence and political sensitivity of protests. This reflects the role of China's official ideology (rule by law and party ideology) in the 'depoliticization' of rural protesters.
\end{abstract}

Keywords: collective action frame (CAF), party ideology, rule by law, civil rights, rural protests, land acquisition

DOI: 10.17323/727-0634-2018-16-2-327-340

\section{References}

Cheng X. (2012) Cong zhengzhi huhao dao falv luoji - dui Zhongguo gongren kangzheng zhengzhi de huayu fenxi [From Politial Slogans to Logic of Law]. Kaifang shidai [Open Times], (11): 73-89.

\footnotetext{
Yan Liu - Researcher, Center for Chinese Rural Studies, Central China Normal University, Wuhan, China.Email: karenly_62@mail.ru
} 
Feng X. (2013) China: Solidarity under a Song: What a Strike Tells Us. Available at: https:// www.iea-nantes.fr/rtefiles/File/china.solidarity-under-a-song.pdf (accessed 10 May 2017).

Franceschini I., Siu K., Chan A. (2016) The 'Rights Awakening' of Chinese Migrant Workers: Beyond the Generational Perspective. Critical Asian Studies, 48 (3): 422-442.

Goffman E. (1986) Frame Analysis: An Essay on the Organization of Experience. Boston: Northeastern University press.

Guo X. (2001) Land Expropriation and Rural Conflicts in China. The China Quarterly, (166): 422-439.

Hess S. (2015) Foreign Media Coverage and Protest Outcomes in China: The Case of the 2011 Wukan Rebellion. Modern Asian Studies, 49 (1): 177-203.

He S., Xue D. (2014) Identity Building and Communal Resistance against Landgrabs in Wukan Village, China. Current Anthropology, 55 (9): 126-137.

He X. (2010) Diquan de luoji [The Logic of Land Rights]. Beijing: Zhongguo zhengfa daxue chubanshe.

Honneth A. (1996) The Struggle for Recognition: The Moral Grammar of Social Conflict. Cambridge: MIT Press.

Hou Y. (2013) The Role of Religious Force in the Wukan Incident. The China Nonprofit Review, 5 (1): 155-175.

Hua R., Hou Y., Deng G. (2016) Instrumental Civil Rights and Institutionalized Participation in China: A Case Study of Protest in Wukan Village. VOLUNTAS: International Journal of Voluntary and Nonprofit Organizations, 27 (5):2131-2149.

Koopmans R., Statham P. (1999) Ethnic and Civic Conceptions of Nationhood and the Differential Success of the Extreme Right in Germany and Italy. In: M. Giugni, D. McAdam, C. Tilly (eds.) How Social Movements Matter. Minneapolis: University of Minnesota Press:225-251.

Li L. (2010) Rights Consciousness and Rules Consciousness in Contemporary China. The China Journal, (64): 47-68.

Lin S., Chen C. (2008) 'Binhai mingzhu' shu Wukan [Wukan as the 'Pearl of the Coastal Guangdong']. Shantou ribao [Shantou Daily]. Available at: http://www.shanwei.gov.cn/ html/2008/11/124415.html (accessed 10 May 2017).

Lu Y., Zheng W., Wang W. (2017) Migration and Popular Resistance in Rural China: Wukan and Beyond. The China Quarterly, (229): 1-22.

McCarthy J., Zald M. (1977) Resource Mobilization and Social Movements: A Partial Theory. American Journal of Sociology, 82 (6): 1212-1239.

McAdam D. (1982) Political Process and the Development of Black Insurgency, 19301970. Chicago: University of Chicago Press.

Michelson E. (2007) Climbing the Dispute Pagoda: Grievances and Appeals to the Official Justice System in Rural China. American Sociological Review, 72 (3): 459-485.

Morris A. (1984) The Origins of the Civil Rights Movement: Black Communities Organizing for Change. New York: Free Press. 
O’Brien K., Li L. (2006) Rightful Resistance in Rural China. Cambridge: Cambridge University Press.

Ong L. (2012) Prosper or Perish: The Political Economy of Credit and Fiscal Systems in Rural China. Ithaca: Cornell University Press.

Perry E. (2008) Chinese Conceptions of 'Rights': From Mencius to Mao - and Now. Perspectives on Politics, 6 (1):37-50.

Perry E. (2007) Studying Chinese Politics: Farewell to Revolution? The China Journal, (57): 1-22.

RTHK (Radio Television Hong Kong) (2012) Bukao shenxian huangdi, zhikao women ziji [No One will Save Us, No God, No King. We are on Our Own]. Available at: https://www. youtube.com/watch?v=JIE3PDHnjDY (accessed 2 August 2017).

Runciman W.G. (1966) Relative Deprivation and Social Justice: A Study of Attitudes to Social Inequality in Twentieth-Century England. Berkeley: University of California Press.

Scott J.C. (1985) Weapons of the Weak: Everyday Forms of Peasant Resistance. New Haven: Yale University Press.

Shih Y-K. (2010) The Isomorphism of Family and State and the Integration of Church and State: On the Differences between the Confucian Political Tradition and Democratic Politics. T. Cao, X. Zhong, K. Liao (eds.) Culture and Social Transformations in Reform Era China. Leiden: Brill:97-118.

Snow D., Benford R. (1988) Ideology, Frame Resonance, and Participant Mobilization. International Social Movement Research, 1 (1): 197-217.

Snow D., Rochford B. Jr., Worden S., Benford R. (1986) Frame Alignment Processes, Micromobilization, and Movement Participation. American Sociological Review, 5 (1): 464-481.

Steinberg M. W. (1998) Tilting the Frame: Considerations on Collective Action Framing from a Discursive Turn. Theory and Society, (27): 845-872.

SunTV (2012) Wukan. Available at: https://www.youtube.com/watch?v=xYFK1DwEGhc (accessed 2 August 2017).

Tarrow S. (1983) Struggling to Reform: Social Movements and Policy Change during Cycles of Protest. Western Societies Program Occasional Paper, Vol. 15. Ithaca: Cornell University Press.

Wang H., Connery C. (2006) Depoliticized Politics, Multiple Components of Hegemony, and the Eclipse of the Sixties. Inter-Asia cultural studies, 7 (4): 683-700.

Williams R. (1977) Marxism and Literature. Oxford: Oxford University Press.

Yeh E. T., O'Brien K., Ye J. (2013) Rural Politics in Contemporary China. Journal of Peasant Studies, 40 (6): 915-928.

Ying X. (2007) 'Qi' yu Zhongguo xiangcun jiti xingdong de zaishengchan ['Qi' and the Reproduction of Collective Actions in Rural China]. Kaifang shidai [Open Times], (6): 106-120.

Yu J. (2009) Dangdai woguo quntixing shijian de zhuyao leixing ji qi jiben tezheng [Major Types and Basic Characteristics of Massive Incidents in Today's China]. Zhongguo zhengfa daxue bao [Journal of CUPL], (6): 114-120, 160. 
Zhang J. (2012) Wukan! Wukan! Available at: https://www.youtube.com/watch?v=Lb_ tto2GwoU\&t=59s (accessed 2 August 2017).

Zhang W. (2015) Protest Leadership and State Boundaries: Protest Diffusion in Contemporary China. The China Quarterly, (222):360-379.

Zhuang H. (2009) Women bushi wangcunnu [We will Not be Slaves without Our Village]. Available at: http://cnlaf.blogspot.ru/2011/09/blog-post_29.html (accessed 2 August 2017).

Zeng Z., Zhang Y. (2015) Zhengshang guanxi de dijie, guhua yu wajie: Wukan tudi kangzheng zhong de difang zhengfu zizhu xing yu shehui liliang [The Establishment, Stabilization and Collapse of the Government-business Relations: The Autonomy of Local Government and Social Power in Wukan's Struggle for Land]. Gonggong guanli pinglun [China Public Administration Review], (20): 73-94.

Zeng Z. (2013) Wukan: the Whole Story. The China Nonprofit Review, 5 (1): 17-101.

Zuo J., Benford R. (1995) Mobilization Processes and the 1989 Chinese Democracy Movement. The Sociological Quarterly, 36 (1): 131-156.

Zweig D. (2016) Freeing China's Farmers: Rural Restructuring in the Reform Era. London: Routledge.

Zweig D. (2010) To the Courts or to the Barricades: Can New Political Institutions Manage Rural Conflict? E. Perry, M. Selden (eds.) Chinese Society: Change, Conflict and Resistance. London: Routledge: 123-147. 